\title{
EDUCAÇÃO AMBIENTAL COMO FERRAMENTA NA MITIGAÇÃO DE CONFLITOS NA BACIA HIDROGRÁFICA DO RIO GRANDE, OESTE DA BAHIA
}

\author{
C. A. P. SANTOS ${ }^{1}$ \\ ${ }^{1}$ Universidade do Estado da Bahia - UNEB/Campus II \\ crispereira@uneb.br
}

Artigo submetido em 09/03/2015 e aceito em 17/12/2016

DOI: 10.15628/holos.2016.2837

\section{RESUMO}

Os conflitos socioambientais ocasionados pelos usos indiscriminados dos recursos hídricos numa bacia hidrográfica têm sido pauta de diversos debates técnicocientíficos e políticos. O artigo pretende discutir a importância da Educação Ambiental na mediação dos conflitos socioambientais gerados pelo uso e ocupação do solo em bacias do rio Grande sob o enfoque da conservação dos recursos hídricos. O método utilizado tem caráter exploratório e descritivo, por meio de levantamento de dados primários, visitas de campo, coleta de material fotográfico e tratamento de imagem de satélite TM/Landsat- 5 e dados secundários, tais como consulta a artigos científicos, legislações ambientais, livros didáticos e outros, que pudessem nortear a influência da Educação Ambiental na mitigação de problemas hídricos. A bacia do rio Grande está representada por um importante pólo agroindustrial e seus principais usos envolvem o abastecimento público, geração de energia elétrica e irrigação, com evidências de conflitos pelo uso da água. Diante da complexidade das questões que afetam a bacia do rio Grande e na busca de um entendimento e na mitigação destas, torna-se necessário a integração da sociedade civil com os poderes públicos para a gestão deste recurso natural, assim como da urgência da criação de um Comitê na bacia de estudo.

PALAVRAS-CHAVE: recurso hídrico; participação social; problemas socioambientais; empoderamento ambiental.

\section{ENVIRONMENTAL EDUCATION AS TOOL IN THE MITIGATION OF CONFLICTS IN RIO GRANDE BASIN, WESTERN OF BAHIA}

\begin{abstract}
Environmental conflicts caused by the indiscriminate use of water resources in a hydrographic basin have been the agenda of various technical-scientific and political debates. The article discusses the importance of Environmental Education in the mediation of environmental conflicts generated by the use and occupation of land in the rio Grande basin as regards the conservation of water resources. The method used is exploratory and descriptive, through primary data collect, field visits, photographic collect and satellite image processing TM/Landsat- 5 and secondary data, such as consultation papers, environmental legislation,
\end{abstract}

textbooks and other, which could guide the influence of Environmental Education in mitigating water problems. The basin of the rio Grande is represented by an important agribusiness pole and its main uses involve the public water supply, power generation and irrigation, with evidence of conflicts over water use. Given the complexity of the issues affecting the basin of the rio Grande and in the search for understanding and mitigating these, the integration of civil society and the public authorities for the management of this natural resource it is necessary, as well as the urgency of creating a Committee in the study basin.

KEYWORDS: water resources; social participation; socioenvironmental problems; environmental empowerment. 


\section{INTRODUÇÃO}

As temáticas ambientais, aqui representadas, pelas situações-problema ou pelos conflitos socioambientais ocasionados pelos usos indiscriminados dos recursos naturais, mais especificamente, pelos recursos hídricos numa bacia hidrográfica têm sido pauta de diversos debates técnico-científicos e políticos. Porém, tem-se observado que as mediações desses conflitos têm sido feitas sem a devida inclusão social de todos os integrantes e usuários da bacia.

Estas situações-problema são decorrentes da apropriação dos recursos naturais, consequência do processo de expansão do capitalismo desenfreado, e neste sentido, torna-se imprescindível ampliar e disseminar as discussões ambientais não só em âmbitos globais como também em âmbitos regionais e, especialmente, locais e assim garantir a participação da comunidade local, usuária do recurso, no processo de planejamento de uso, com destaque a sua valorização e problematização dos possíveis conflitos.

O processo de ocupação e uso do solo na região Oeste da Bahia, resultante da abertura da fronteira agrícola ocorrida na metade da década de 80, é um dos fenômenos determinantes do espaço agrário. E esta ocupação é proveniente tanto da crescente expansão das atividades agropecuárias como da urbanização evolutiva, observadas nas últimas décadas, e responsáveis pela alteração das paisagens nesta região.

A fronteira agrícola no Oeste da Bahia ocorreu especialmente pela imigração de agricultores provenientes de outras regiões, como exemplo, a chegada dos sulistas, determinantes para o avanço agrícola, pois trouxeram contigo toda experiência agrícola vivida na era da modernização agrícola, ou seja, o conhecimento de que o aumento do ciclo produtivo estava associado à implementação do pacote tecnológico, fruto do processo da Revolução Verde.

No Oeste da Bahia estão concentrados $92 \%$ de toda a produção de grãos, de todo o Estado da Bahia (1,8 milhões de hectares), que pode ser interpretado pelo aumento de área plantada e da produtividade, o que representa algo em torno de $35 \%$ de todo grão produzido no país, sendo a soja, o algodão e o milho os principais produtos agrícolas. Esta região tão importante para o cenário agrícola do país, também é uma região rica em biodiversidade e em recursos hídricos, sendo conhecido como "Berço das Águas". No entanto, a paisagem natural do Cerrado baiano parece estar violentamente ameaçada pelo desenvolvimento econômico regional, visto que a utilização dos recursos naturais é mediada pela ótica do capitalismo.

A proposta deste artigo surgiu a partir da percepção de que a bacia do rio Grande, área de estudo, é também uma área de expansão de fronteira agrícola, e por esta razão o uso e a ocupação do solo desta bacia provocam impactos negativos sobre os recursos hídricos, com geração de conflitos pelos diversos usuários da bacia, os quais por sua vez, em função das desigualdades sociais e de conhecimento acabam por corroborar com a degradação deste recurso. Desta maneira, configura-se como objetivo discutir a importância da Educação Ambiental na mediação dos conflitos socioambientais gerados pelo uso e ocupação do solo em bacias do rio Grande, no que se diz respeito à conservação dos recursos hídricos, por meio de uma abordagem teórico-metodológica. 


\section{REVISÃO LITERÁRIA}

\subsection{Bacia hidrográfica como unidade de planejamento}

As bacias hidrográficas são definidas como um “(...) ecossistema hidrologicamente integrado, com componentes e subsistemas interativo", e com "abordagem adequada para proporcionar a elaboração de um banco de dados sobre componentes biogeográficos, econômicos e sociais", que promovem a "integração de cientistas, gerentes e tomadores de decisão com o público em geral, permitindo que eles trabalhem juntos em uma unidade física com limites definidos" (TUNDISI e MATSUMURA-TUNDISI, 2011, p.154), sendo, portanto, um ambiente de oportunidade para o desenvolvimento de parcerias e resolução de conflitos socioambientais (SAITO et al., 2011).

Independentemente destas distintas abordagens, percebe-se que o conceito de uma bacia hidrográfica vai além dos limites geográficos, sendo ela entendida, segundo a Política Nacional de Recursos Hídricos (PNRH), como unidade territorial de gestão dos recursos hídricos e numa forma mais ampla como uma unidade de planejamento e gerenciamento ambiental com capacidade de integração de fatores socioambientais (BERLINCK et al., 2003; BERGMANN e PEDROZO, 2008).

Esta unidade possibilita a vantagem de um gerenciamento simultâneo, interdependente e cumulativo de seus aspectos econômicos, sociais e ambientais, através da possibilidade de realizar um planejamento e administração integrada dos recursos naturais, solo e água, ampliando assim, notavelmente, a sinergia e a potencialidade dos processos operados, discutidos dentro da Teoria dos Sistemas, onde as partes são compreendidas a partir da organização do todo (LIMA e PONTE, 2009) e, neste sentido, é essencial para se avaliar as relações de causa e efeito de atividades antrópicas sobre o comportamento ambiental, isto porque é a unidade mais apropriada para o gerenciamento, otimização de usos múltiplos e o desenvolvimento sustentável. Este tipo de análise possibilita a instalação de um processo de investigação-ação participativo, visto que a unidade passa a ser objeto de defesa por todos os grupos inseridos na bacia, e não mais no âmbito individual.

\subsection{Educação ambiental e conflitos socioambientais}

O meio ambiente é considerado como um bem social de domínio público. Por esta razão, a apropriação particular e irracional deste bem evidencia diferentes impactos ambientais, como a exemplo, a redução da disponibilidade do recurso hídrico, que por sua vez são socializados entre os distintos múltiplos usuários de uma bacia hidrográfica. A esta dinâmica de apropriação do recurso, por interesses particulares (individuais ou coletivos), e a socialização de situaçõesproblema a todos os usuários, independentemente de quem seja o poluidor, configura a geração de conflitos socioambientais e a Educação Ambiental parece ser uma valiosa ferramenta na mitigação desses conflitos.

Em termos conceituais, cabe esclarecer que a Educação Ambiental, sobre a ótica da Lei 9.795/99, está definida como um conjunto de procedimentos que permitem a construção de valores sociais, conhecimentos, habilidades, atitudes e competências à conservação do meio 
ambiente (...). E apresenta princípios básicos fundamentais à garantia mínima dessa conservação, como: (i) o enfoque humanístico, holístico, democrático e participativo; (ii) a concepção do meio ambiente em sua totalidade, considerando a interdependência entre o meio natural, o socioeconômico e o cultural, sob o enfoque da sustentabilidade e a (vii) abordagem articulada das questões ambientais locais, regionais, nacionais e globais (BRASIL, 1999, p. 1).

A terminologia conflitos socioambientais refere-se à existência de situações-problema presentes no âmbito social e que gera impactos ambientais sobre a biodiversidade (SAITO et al., 2008). Ou, como disputas entre diversos grupos sociais que utilizam de formas distintas os recursos do ambiente, gerando conflito de interesses ou de afrontamento entre esferas heterogêneas a partir de relações de poder e de controle social (SUASSUNA, 2005; CUNHA, 2006). De uma forma mais ampla, “(...) eles se dão pelo uso ou apropriação de espaços e recursos coletivos por agentes econômicos particulares, pondo em jogo interesses que disputam o controle dos recursos naturais e o uso do meio ambiente comum..." (SCOTTO, 1997, p. 4 apud SAITO et al., 2011).

O conceito socioambiental envolve três dimensões básicas: o mundo biofísico e seus múltiplos ciclos naturais, o mundo humano e suas estruturas sociais, e o relacionamento dinâmico e interdependente entre estes dois mundos (CUNHA, 2006), demonstrando a complexidade do tema e que ao contrário das atuais ações humanas, o homem não é um ser externo à natureza, nem tampouco à natureza é um elemento estranho ao ser humano.

Não há dúvidas de que para a mitigação destes possíveis conflitos socioambientais, a adoção de um novo paradigma, de novos conhecimentos teóricos e práticos, para a compreensão e resolução destes conflitos, torna-se indispensáveis. A consequência dessa mudança de paradigma é a geração de um saber solidário e de um pensamento complexo, aberto às indeterminações, às mudanças, à diversidade, à possibilidade de construir e reconstruir num processo contínuo de novas possibilidades de ação (JACOB et al., 2009). Diante desta nova postura, deste novo olhar sob os recursos naturais, Dias (1998 apud BERNARDES e PRIETO, 2010, p. 179) considera a Educação Ambiental como "um conjunto de conteúdos e práticas ambientais, orientadas para a resolução dos problemas concretos do ambiente, por meio do enfoque interdisciplinar e de uma participação ativa e responsável de cada indivíduo e da comunidade".

Em se tratando desta participação ativa da sociedade, o que se tem percebido é que as relações de domínio dos recursos naturais, sobretudo dos recursos hídricos, expressos sobre a figura dos múltiplos usuários, determinam a diferença do acesso a estes recursos de melhor qualidade, fruto provavelmente de distintas realidades políticas, econômicas, sociais, culturais, bem como questões ecológicas (MELAZO, 2005). E desta maneira, aqueles usuários desprovidos de conhecimentos técnico-científicos, necessários à intervenção na formulação das políticas públicas, reguladoras do recurso, ficam à margem do processo decisório de gerenciamento dos recursos hídricos. Constata-se, então, uma inobservância dos interesses do bem estar social em pró do atendimento de interesses particulares, que contraria os princípios norteadores da Política Nacional de Educação Ambiental que são a conscientização e as ações coletivas (BERLINCK et al., 2003). E o resultado deste modelo de gerenciamento se resume no aumento do uso irracional do recurso hídrico, baseado por uma equivocada concepção de que estes recursos 
são simplesmente inesgotáveis, promovendo grandes disparidades sociais seguidas por distintos dilemas e conflitos.

O entendimento das relações sociedade-ambiente depende de um contínuo resgate e/ou desenvolvimento da percepção ambiental do indivíduo mediante um novo olhar sobre o ambiente, de forma a delinear ações e programas de Educação Ambiental sobre o uso sustentável dos recursos hídricos (CARVALHO et al., 2012). A percepção ambiental no indivíduo é a base que melhor garante a compreensão dessas relações por meio do conhecimento de suas satisfações e insatisfações, condutas e expectativas para, a partir daí, buscar a percepção que o outro tem sobre o ambiente de conflito (BEZERRA et al., 2008).

Para que a Educação Ambiental atinja os seus objetivos, a percepção ambiental e a inserção social tornam-se determinantes no processo de resolução dos problemas ambientais, sobretudo, na mitigação dos conflitos socioambientais ocorridos numa bacia hidrográfica. A percepção ambiental juntamente à Educação Ambiental favorece, além do uso racional dos recursos hídricos, a promoção de uma “(...) relação mais harmônica do ponto de vista de um indivíduo ou de uma coletividade com os elementos exteriores, sejam estes, elementos naturais, necessidades econômicas, ou interesses político-sociais (MELAZO, 2005, p. 49)”.

Num verdadeiro processo de Educação Ambiental, é inevitável a existência do confronto de opiniões e valores que estão cristalizados no imaginário das pessoas (REIGOTA e SANTOS, 2005). A contextualização da temática ambiental pela Educação Ambiental deve adotar os conflitos socioambientais como princípios metodológicos de forma que os conflitos socioambientais e os processos de Educação Ambiental estejam intrinsecamente articulados. Estes conflitos possibilitam trabalhar questões de dimensões da realidade extra-ambientais como de natureza política, democrática, valorativas e judiciais. Além disso, os potenciais educativos, por meio de trabalhos contextualizados favorecem o estreitamento do entendimento dos conflitos, de modo a promover debates políticos e de valores e, sobretudo, formar cidadãos ativos (SAITO, 2009; SAITO et al., 2011).

Somente a partir da problematização dos conflitos a Educação Ambiental pode promover práticas sociais baseadas na racionalidade e na justiça. Isto porque desempenha um papel vital em relação ao comportamento humano sobre o meio ambiente e, sobre as questões sociais: promoção de uma efetiva mudança de valores e atitudes, a favor de práticas sociais cooperativistas e não mais individualista (BERLINCK et al., 2003), tornando o indivíduo com capacidade de leitura crítica à realidade onde atua (SAITO et al., 2011), mediante a sua instrumentalização técnica-científica, para de fato, tornar a gestão participativa e descentralizadora do recurso natural pretendido.

\section{METODOLOGIA}

A bacia hidrográfica do rio Grande está localizada ao Norte com o Estado do Piauí, ao Sul com a bacia do rio Corrente, ao Leste com as bacias do Médio São Francisco e ao Oeste com os Estado de Goiás e Tocantins, nos paralelos $10^{\circ} 10^{\prime}$ e $13^{\circ} 20^{\prime}$ de latitude sul e os meridianos $43^{\circ} 08^{\prime}$ e $46^{\circ} 37^{\prime}$ de longitude oeste Gw, o que representa 13,2 \% a área de todo o Estado da Bahia. Apresenta uma pluviosidade anual que varia de 800 a $1700 \mathrm{~mm}$, com dois períodos climáticos 
bem definidos, seco e chuvoso, e temperatura média anual de $25,9^{\circ} \mathrm{C}$ no período seco e $22,2^{\circ}$ no período chuvoso, o que possibilita diferentes tipos de fitofisionomias vegetais, típicas do bioma Cerrado. Possui relevo composto das unidades morfoesculturais de planalto, planalto em patamar, depressão e serras (MOREIRA e SILVA, 2010). É um dos afluentes mais importantes do trecho médio rio São Francisco e com uma área de $75.000 \mathrm{~km}^{2}$, contribui com $25 \%$ da vazão total do rio São Francisco, o que representa uma vazão média anual de $262 \mathrm{~m}^{3} / \mathrm{s}$ (SILVA e LANNA, 1997).

A Figura 1 ilustra a subdivisão da bacia em oito sub-bacias: a do rio Preto, Baixo rio Grande, rio Branco, Médio rio Grande, rio de Ondas, São Desidério, rio das Fêmeas e Alto rio Grande. As sub-bacias do rio Preto, rio Branco e rio de Ondas são as que apresentam maiores atividades agropecuárias seguidas de maiores taxas de desmatamento, ou seja, de conversão de áreas com cobertura vegetal natural para áreas antropizadas.

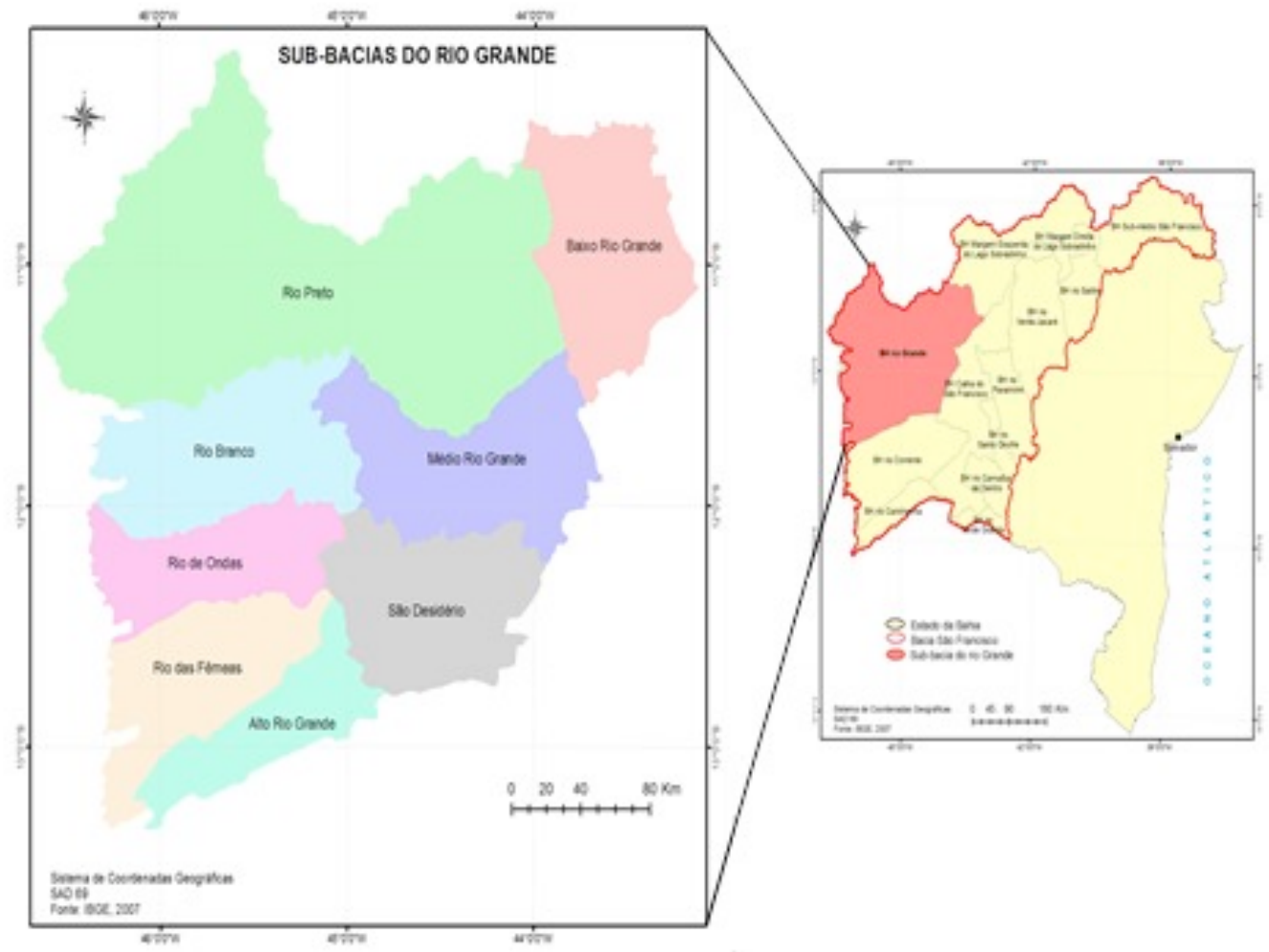

Figura 1: Localização da bacia do rio Grande na região Oeste da Bahia.

O rio Grande é o principal rio da bacia, com nascente localizada entre a divisa dos Estados de Goiás e Bahia, desaguando no rio São Francisco, município de Barra, após percorrer uma extensão de 502 km. Incluem no território da bacia os seguintes municípios: Angical, Baianópolis, Barra, Barreiras, Buritirama, Catolândia, Cotegipe, Cristópolis, Formosa do Rio Preto, Luís Eduardo Magalhães, Mansidão, Muquém do São Francisco, Riachão das Neves, Santa Rita de Cássia, São Desidério, Tabocas do Brejo Velho e Wanderley (MOREIRA e SILVA, 2010).

O presente trabalho tem caráter exploratório e descritivo por meio de levantamento de dados primários, por meio de visitas de campo, com coleta de material fotográfico e tratamento de imagem de satélite TM/Landsat-5 datada de 28/10/2011, a fim de se identificar pontos de 
erosão e de ocupação irregular em áreas de preservação permanente (APP) na área de estudo, utilizando o ArcView 9.3. Além de dados secundários, tais como consulta a artigos científicos, legislações ambientais, livros didáticos e outros, que pudessem nortear a influência da Educação Ambiental na mitigação de problemas hídricos.

Esses dados tratam de conceitos sobre os temas abordados, a importância da EA numa situação de conflito existente por um recurso natural, além de demostrar os principais impactos ambientais negativos por ação antrópica na bacia hidrográfica de estudo e suas possíveis mitigações.

Adotou-se, nesta ótica, a dialogicidade como elemento central da ação educacional norteada por uma discussão teórico-metodológica, segundo o pressuposto crítico da metodologia dialógica-problematizadora (FREIRE, 1987), frente às diversas situações-problemas ocorridas pela disputa de um recurso natural de relevância social.

\section{RESULTADOS E DISCUSSÃO}

4.1 Principais conflitos gerados pela alteração da paisagem natural da bacia hidrográfica do rio Grande

A bacia do rio Grande está representada por um importante pólo agroindustrial, e seus principais usos envolvem o abastecimento público, a geração de energia elétrica e a irrigação, com evidências de conflitos pelo uso da água. A partir desses diversos usos, ao longo da área da bacia hidrográfica, surgem os distintos conflitos. E, os problemas advindos destes conflitos são gerados em grande parte pela inexistência de um programa de planejamento ambiental associado intrinsecamente a programas de Educação Ambiental que, veja a questão ambiental indissociável aos problemas sociais, pois “(...) nenhum planejamento de caráter ambiental se efetiva, verdadeiramente, sem a participação popular e sem uma forte proposta de educação ambiental" (REIGOTA e SANTOS, 2005, p. 849).

Segundo dados do próprio órgão ambiental, Instituto de Meio Ambiente e Recursos Hídricos (INEMA), o comprometimento de $100 \%$ da vazão de disponibilidade hídrica na bacia do rio Grande é, na atualidade, uma realidade. Neste sentido, evidencia-se que a demanda de água pela agricultura irrigada (pivô central) nesta bacia configura-se a uma vazão de $6.464 .448 \mathrm{~m}^{3} / \mathrm{dia}$ ou $74,82 \mathrm{~m}^{3} / \mathrm{s}$, numa área de 82.837 ha irrigados, sendo que $6.004 .800 \mathrm{~m}^{3} /$ dia refere-se à demanda de água superficial e $459.648 \mathrm{~m}^{3} /$ dia a demanda de água subterrânea. Estes dados resultam na impossibilidade de se emitir novas outorgas de uso e captação de água para quaisquer atividades.

Nos últimos trinta anos de ocupação do Cerrado baiano, o rápido desenvolvimento econômico, o crescimento populacional e da produtividade agrícola trouxeram como preocupação a disponibilidade de água, e de qualidade, para atendimentos dos múltiplos usuários da bacia, haja vista que o aumento da pressão sob os recursos naturais, pelo homem no sistema capitalista, tem provocado degradação do solo como consequência dos processos de erosão e sedimentação de rios na região. Uma prova disto refere-se à perda de Cerrado para as 
atividades agrícolas na região Oeste da Bahia de aproximadamente $9.266 \mathrm{Km}^{2}$ (6,01\%) ocorrida entre os períodos de 2002 e 2008 (BRASIL, 2010).

Estes dados são tidos como reflexos do atual modelo de desenvolvimento econômico e em virtudes das grandes potencialidades naturais existentes coloca a bacia do rio Grande em situação alarmante, pois quatro dos quatorzes municípios pertinentes à bacia estão no ranking dos vinte municípios que mais desmatam no Cerrado brasileiro, sendo Formosa do Rio Preto, São Desidério, Barreiras e Riachão das Neves. Destes, os dois primeiros municípios lideram o ranking ocupando a primeira e a segunda posição, respectivamente, enquanto que o município de Barreiras ocupa a décima quarta posição e Riachão das Neves a décima sétima.

A agricultura vem contribuindo de forma acentuada para a degradação da qualidade da água mediante o lançamento, mesmo que indireto, de poluentes na água, como agrotóxicos, sedimentos, fertilizantes, adubo animal e outras fontes de matéria orgânica e inorgânica, os quais chegam a atingir as fontes de água superficial e subterrânea durante o processo de escoamento e percolação, chamadas de fontes não-pontuais de poluição (MARQUES et al, 2007). Isto contribui para alterar a dinâmica natural dos ecossistemas, poluição concentrada, problemas de drenagem, assoreamento dos corpos d'água, redução da taxa de infiltração no solo com consequente aumento da velocidade de escoamento da água, eutrofização, perda da biodiversidade ictiológica, dentre outros.

A contaminação da água por despejos excessivos de agrotóxicos na agricultura moderna tem sido considerada um grave problema de contaminação química. Estes compostos químicos e seus derivados tornaram-se uma ameaça à saúde humana e à saúde ambiental. Nesta linha, ao considerar uma área de plantio de aproximadamente 1 milhão (ha) (Safra 2010/2011), bem como a aplicação de 3,2 kg/ha de agrotóxicos no plantio da soja, terá como resultado uma aplicação de 32 t agrotóxicos/safra, quantidade extremamente excessiva de agrotóxicos e de 218 t agrotóxico/safra para a cultura de algodão, considerando uma área de 370 mil ha plantados (Tabela 1).

Tabela 1: Consumo de agrotóxicos por unidade de área em algumas culturas agrícolas no Brasil, em quantidade de ingredientes ativos para o ano de 1998.

\begin{tabular}{c|c|}
\hline Cultura & Quantidade $\left(\mathrm{kg} . \mathrm{ha}^{-1}\right)$ \\
\hline Tomate & 52,5 \\
Batata & 28,8 \\
Citros & 12,4 \\
Algodão & 5,9 \\
Café & 4,2 \\
Soja & 3,2 \\
Cana-de-açúcar & 2,0 \\
Geral & 2,9 \\
\hline
\end{tabular}

Fonte: SPADOTTO et al. (2004). 
Ressalta-se que na região Oeste há também plantios, além da soja, de algodão (segunda maior cultura na região), café e milho, todos em grande parte irrigados, o que contribui, sem dúvidas, para a degradação da qualidade da água na bacia de estudo.

A agricultura de subsistência, apesar de ser realizada em pequena escala, pelas comunidades rurais no interior da bacia também oferece impacto ambiental negativo sobre a qualidade da água, em função da aplicação de agrotóxicos e do plantio realizado sem orientações técnicas de manejo. Por outro lado, estas mesmas comunidades também são as mais receptivas para a realização de projetos de Educação Ambiental, as quais mesmo excluídas do processo econômico são vistas como aquelas que apresentam as melhores intenções de participação de programas de conservação ambiental.

Trabalhos como de Guadagnin et al. (2011) demonstram o impacto do agronegócio sobre o regime hídrico na bacia do rio Grande, em especial a sub-bacia do rio das Fêmeas, cujo resultado baseou-se na apresentação da supressão da vegetação ciliar em áreas urbanas e rurais do município de Barreiras durante o ano de 2008, cujo resultado foi a obtenção da taxa de supressão de $16 \%$ nas áreas de APP, observada em vários trechos da paisagem, aspectos de interrupção do curso d'água na bacia, reflexo da substituição da vegetação ciliar pela agricultura (Figura 2).

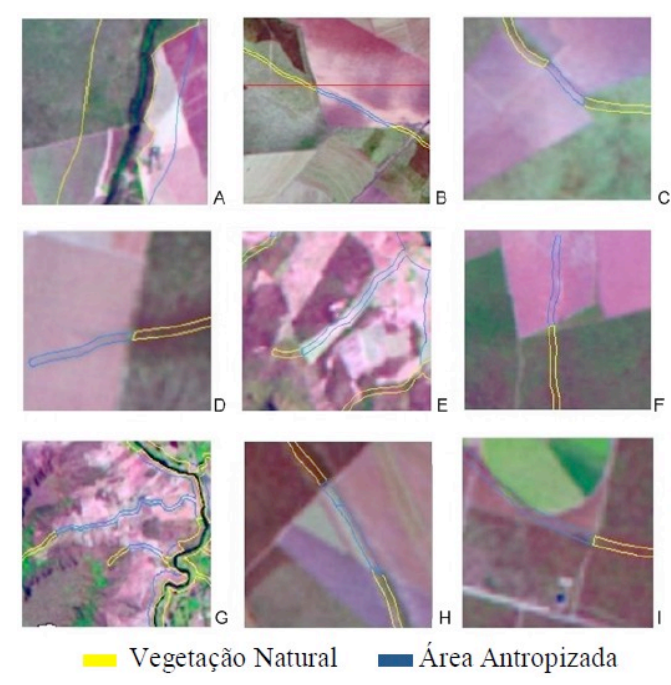

Figura 2: Supressão da vegetação ciliar no município de Barreiras. Fonte: GUADAGNIN et al. (2011).

A Figura 3 ilustra, mais uma vez, a ocupação irregular da mata ciliar na bacia do rio Grande. Nesta imagem é evidente a substituição da referida mata pela agricultura irrigada, ferindo o Código Florestal, onde define APP como áreas cobertas ou não por vegetação nativa, com a função ambiental de preservar os recursos hídricos, a paisagem, a estabilidade geológica, a biodiversidade, o fluxo gênico de fauna e flora, proteger o solo e assegurar o bem-estar das populações humanas (BRASIL, 1965), sendo, portanto a exploração desta área proibida por lei. Além das instalações de pivôs centrais nestas áreas, também é perceptível cicatrizes de queimadas, fruto do tipo de manejo adotado de alto impacto, que para preparar o terreno para o plantio ou simplesmente para a sua limpeza, utiliza-se desta prática sem uma devida técnica de controle. 
Uma consequência drástica desta utilização indiscriminada da queimada pela agricultura refere-se à destruição de veredas que alimentam o rio dos Cachorros na sub-bacia do rio das Fêmeas, com escassez na disponibilidade hídrica (Figura 4).

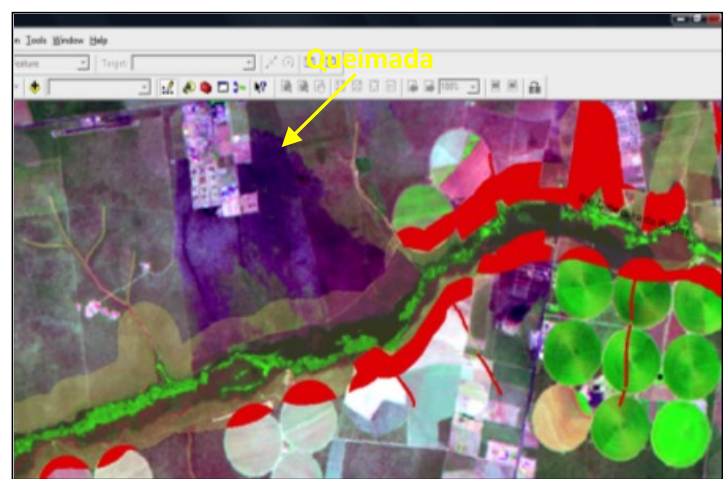

Figura 3: Ocupação irregular da agricultura sobre a APP, representada pela coloração vermelha, na sub-bacia do rio das Fêmeas.

Fonte: Autor (2013).

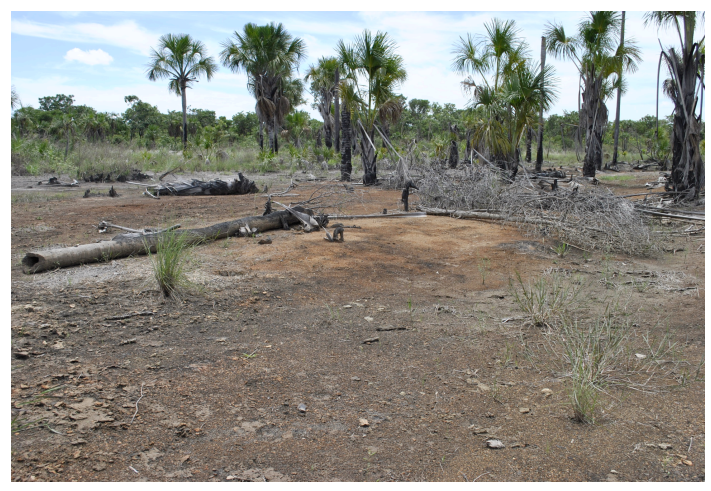

Figura 4: Vereda com evidências de fogo e deficiência de água na área.

Fonte: Autor (2013).

Estas situações apresentadas remetem a hipótese de que a problemática em torno da conservação dos recursos hídricos tem sido, na maioria dos casos, negligenciadas por boa parte das pessoas, inclusive daquelas tomadoras de decisões, como a exemplo os órgãos e autoridades competentes a este fim.

Então, a pergunta que se deve fazer é a seguinte: É possível conciliar a produção agrícola com a conservação dos recursos naturais? Ou melhor, é possível expandir a produtividade agrícola sem adoção de manejos que visem respeitar o limite ambiental do ecossistema? E mais, qual o padrão da produtividade a ser alcançado frente a uma escassez hídrica? Questionamentos como estes, não são para hoje, frutos imaginários, e sim passíveis e possíveis de atingir.

Para enriquecer esta discussão é preciso discutir sobre a existência de um debate ocorrente na comunidade científica a respeito da relação da cobertura vegetal e produção de água, onde muitos questionamentos são realizados, mas o que se sabe, é que a vegetação nativa atua no ciclo hidrológico de maneira mais expressiva, que qualquer outro tipo de cobertura vegetal, pois promove melhores taxas de infiltração da água da chuva pelo processo de interceptação pela cobertura vegetal (OLIVEIRA Jr. e DIAS, 2005).

Áreas ecologicamente frágeis (áreas declivosas, nascentes e margens dos rios, áreas de recarga dos aquíferos, etc.) devem ser preservadas ou exploradas por sistemas agroflorestais com baixo impacto ambiental, pela adição de uma matéria orgânica de qualidade, no solo, bem como a manutenção da água no sistema (MERTEN e MINELLA, 2002). E na região do Cerrado, onde a precipitação é estacional, com períodos climáticos bem desenvolvidos (chuva e seca), a preocupação com a conservação da água deve ser maior ainda. Desta forma, o uso e a ocupação dos solos devem priorizar técnicas de manejo que auxiliem na promoção da conservação dos recursos hídricos (ALVARENGA et al., 2010). Neste sentido, a utilização de Sistema de Integração Lavoura-Pecuária-Floresta (ILPF), por exemplo, torna-se uma excelente opção de manejo. 
Em continuidade a esta fragilidade ecossistêmica, a declividade tem um papel fundamental sobre a dinâmica do fluxo da água, visto que à medida que a declividade aumenta, paralelamente aumenta-se também a velocidade de escoamento superficial da água e, com isso, a capacidade de transporte de carreamento de partículas do solo para o leito dos rios altera não somente os processos de vazão, como os de qualidade hídrica deste manancial.

Este tipo de situação já é evidente em alguns pontos da bacia do rio Grande, especificamente na bacia do rio Preto, onde a topografia de algumas áreas torna-se o fator limitante de produtividade. A Figura 5 ilustra uma erosão hídrica ocorrendo numa vereda pertencente ao rio do Sapão, afluente do principal rio da sub-bacia do rio Preto, proveniente do uso e ocupação de solo pela agricultura que se desenvolve num platô sob formação de arenito, responsáveis por provocar alterações na dinâmica natural de fluxo de água nesta sub-bacia.

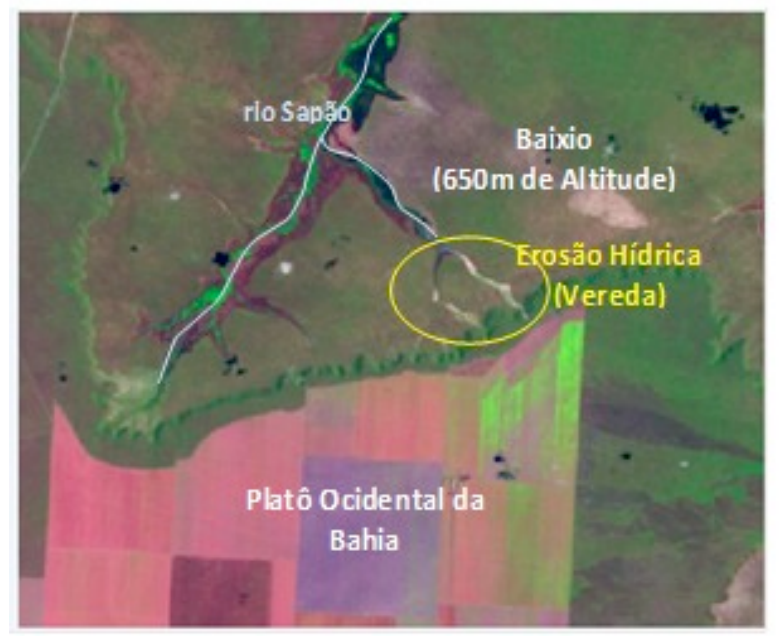

Figura 5: Demonstração da erosão hídrica na sub-bacia do rio Preto, outubro de 2011. Fonte: Autor (2013).

Há a necessidade de ressaltar que o uso deste solo pela agricultura localiza-se no interior de uma Unidade de Conservação de Proteção Integral, a Estação Ecológica Serra Geral do Tocantins, localizada na divisa entre o Estado do Tocantins e o Estado da Bahia, e que de acordo (BRASIL, 2000), o princípio básico desta UC é justamente a preservação da natureza, sendo, portanto, admissível apenas o uso indireto de seus recursos naturais e não a sua exploração direta a fins de comercialização como está apresentado nesta área.

\subsection{Educação Ambiental e mitigação dos conflitos socioambientais na bacia do rio Grande}

As situações de conflito ambiental referentes aos múltiplos usuários da bacia do rio Grande representam desafios para todos os segmentos afetados. Essas situações de conflito assumem interesses singulares do ponto de vista do crescimento econômico por meio da expansão do agronegócio, representados pelos proprietários rurais e pelo Estado, em detrimento dos demais usuários da bacia, em especial, daqueles desprovidos de algum empoderamento, como as comunidades rurais, que sem dúvida alguma são colocados à margem do processo participativo do uso e gestão dos recursos hídricos da bacia e assim são submetidos a aceitar e exercer as decisões emanadas pelo poder e imposto pelo modelo capitalista. Predomina-se então 
a relação de poder dos atores mais fortes, os grandes usuários, corroborada pelo Estado, sobre os atores mais fracos, como os pequenos usuários e a própria sociedade civil, sendo esta relação marcada por uma grande assimetria entre os atores que sofrem os custos e aqueles atores que são beneficiados (BRYANT e BAILEY, 1997).

A inexistência de um comitê de bacias hidrográficas na região favorece positivamente a presença de conflitos socioambientais, isto porque uma das suas funções é justamente arbitrar em primeira instância os conflitos sobre o uso dos recursos hídricos, institucionalizando a gestão participativa em um modelo descentralizado (BERLINCK et al., 2003) e necessário à consolidação de um novo paradigma de planejamento e gerenciamento dos recursos hídricos delimitados pela figura da bacia.

Dado os interesses em jogo e os conflitos que podem existir entre os distintos atores sociais que atuam sobre a bacia do Rio Grande, os processos de uso e gestão dos recursos ambientais, sobretudo os recursos hídricos, são em sua essência, sempre conturbados. Desta forma, se há, por um lado, aqueles que objetivam a posse e o controle deste recurso natural há, por outro lado, a formação de grupos defensores destes recursos e/ou excluídos do processo de ocupação e domínio, gerando, portanto, conflitos individuais e coletivos que se traduzem em dilemas sociais (BERLINCK et al.,2003).

Alguns atores sociais enfatizam os aspectos de degradação no ambiental natural, no que se diz respeito aos recursos hídricos, ocasionados pelo processo de ampliação da economia agrícola, como a exemplo os movimentos ambientalistas e as comunidades rurais sobreviventes. Outros argumentam que a expansão do agronegócio é essencial para produção de alimentos (quando associadas a esquemas de integração vertical com as agroindústrias) e para o progresso da economia brasileira como gerador de emprego, renda e superávit na balança comercial, defendidas pelos produtores rurais e encorajadas pelo Estado.

E assim, deve-se levar em consideração o fato de que a utilização dos recursos hídricos da bacia do rio Grande desconsidera os aspectos referentes à espacialização do uso, isto porque o fato de determinado usuário demandar uma significativa quantidade hídrica sem observação dos efeitos sobre a demanda do usuário a jusante pode causar conflitos entre os diferentes usuários. Mesma situação incide sobre as atividades poluidoras da bacia sem adoção da relação causaefeito quanto aos usuários a montante e a jusante (BERLINCK et al., 2003).

Diante destes argumentos teóricos, há de se observar os reflexos do mito da participação social sobre os conflitos socioambientais, ou melhor, que "a ênfase no mito da participação social permite adentrar também no mito da resolução dos conflitos socioambientais (...), isto porque a (...) participação pode ser desejável no que diz respeito à resolução de conflitos, mas ao mesmo tempo parece relevante averiguar a existência de interesses contraditórios, ou de tal forma opostos, que a participação possa ser irrelevante como possibilidade de resolução desses conflitos socioambientais" (SAITO et al., 2011, p. 125).

De acordo com Santos e Saito (2006, p. 9), a mitificação da participação social na Política Nacional de Recursos Hídricos (PNRH) pode vir a ocorrer, haja vista de que “(...) o conceito de participação é apropriado e deturpado pelo setor dominante da sociedade como forma de obter uma pretensa legitimidade às suas decisões (...)". Trata-se de uma mitificação a partir do 
momento em que a participação da população, de diversos segmentos econômicos, destituídos de argumentos e conhecimentos necessários, não consegue defender e avaliar as reais demandas de uso da água por todos os atores sociais delimitados pela bacia.

Esta situação acontece na bacia do rio Grande, uma vez que apesar da inexistência de disponibilidade hídrica para os agricultores irrigantes, até hoje, há concessão de novas outorgas para essa classe usuária. Vale ressaltar que mesmo antes desta concessão pelo órgão responsável, o mesmo é passado por uma comissão denominada Conselho Municipal de Meio Ambiente (CONDEMA) para discussão das análises ambientais de determinada atividade potencialmente poluidora, tendo na grande maioria dos projetos o parecer positivo.

O CONDEMA é constituído por 18 membros, sendo seis representantes do Poder Público Municipal (secretários e/ou representantes das secretarias de Agronegócio, Meio Ambiente, Infraestrutura, Saúde, Educação e Administração), uma Organização Não Governamental, um representante das universidades públicas e privadas, um das associações comunitárias rurais, um dos sindicatos de trabalhadores e empregados e um das associações comunitárias urbana. Os seis restantes representantes do Poder Econômico (um do setor comercial, um do industrial, um da pecuária, um da pesca e um dos sindicatos patronais, um da agricultura familiar). Observa-se, portanto, que a participação da sociedade, neste Conselho, está representada pela minoria e que a maioria representada pelos demais setores defendem os interesses da agropecuária.

Esta composição demonstra uma noção de desigualdade no poder decisório no processo, corroborada por Santos e Saito (2006, p.11) que afirmam que "o que se apresenta como mitificação da participação, (...), é o fato de que se veicula uma crença de que todos os grupos sociais (poder público, usuários, comunidades) envolvidos numa mesma negociação, estariam participando e contribuindo em iguais condições. A mitificação da participação passa por ignorar a assimetria de poder econômico, de conhecimento técnico-científico, de eloquência na fala e no poder de argumentação, existentes entre os diversos segmentos sociais envolvidos".

Desta maneira fica aqui a pergunta: Como a associação da comunidade rural, agricultura de subsistência, pode participar de um processo de decisão de uso e gerenciamento hídrico diante as demais camadas constituintes do Conselho a fim de opinar, discutir e planejar, de igual para igual, o uso deste recurso? Isto porque as diferenças de interesses, ideologias e formação dos participantes costumam dificultar, e em algumas vezes impossibilitar, a escolha dos melhores cursos de ação e gestão participativa dos recursos hídricos (PORTO e PORTO, 2008).

A visão de preservação dos recursos naturais se fundamenta nas noções da natureza e o homem. Diferenças de significados e percepção dos conjuntos naturais constroem a base dos conflitos socioambientais (CUNHA, 2006). Diante a complexidade destes conflitos socioambientais várias perguntas são constantemente formuladas a fim de permear a busca de ações que possam viabilizar a mitigação destas situações-problemas, visto que o “(...) 0 gerenciamento "ótimo" de bacias hidrográficas de uma determinada região, por exemplo, indicaria em quanto no volume pluviométrico, aumentaria, modificaria, produziria efeitos benéficos ou catastróficos? Em que proporções? Quais e quantos fatores, em escala global, estariam atuando no processo?" (OLIVEIRA, 2009, p.84). 
O que se sabe é que a inserção do indivíduo, como observador dos processos que constituem a dinâmica de uma bacia hidrográfica, é fundamental para a compreensão do meio ambiente no qual se está inserido. E assim, a percepção do ambiente, como compreensão das distintas interações provenientes desta relação, aliada ao conceito de Educação Ambiental e a conscientização ambiental contribuem para a adequada compreensão de situações-problema sob a dinâmica de uma bacia hidrográfica.

Mas como a Educação Ambiental pode contribuir para esta conscientização ambiental e consequentemente para a mitigação dos conflitos socioambientais? Saito et al. (2011) sugerem que a conscientização implica no "engajamento", na construção e mobilização de saberes para emancipação do indivíduo promovido pelo "empoderamento", além da adoção de uma metodologia dialógica e problematizadora segundo a visão Freireana. E segundo Saito et al. $(2008$, p. 5) este fortalecimento, ou o empoderamento “(...) tanto no plano individual (aquisição de conhecimento técnico-científico) como no plano coletivo (aumento no poder de intervenção para transformar a realidade com base no conhecimento técnico-científico) promove a emancipação dos usuários de forma a garantir maior cultura de participação socioeducacional na gestão da bacia hidrográfica. Desta forma, o que se espera é a formação de uma sociedade democraticamente justa e ambientalmente igualitária, em termos de empoderamento, a fim de uma maior participação na tomada de decisão sobre os recursos hídricos, com vistas a erradicar as discussões superficiais e expandir a aplicabilidade dos trabalhos de Educação Ambiental na conscientização dos múltiplos usuários da bacia.

De uma maneira mais ampla, existem múltiplas formas, em diferentes tempos e espaços, de promover a educação para o meio ambiente. A abordagem hídrica, tanto no âmbito formal quanto no informal, pode promover a conscientização ambiental das pessoas, de forma que elas tenham um conjunto de valores que as instrumentalize para perceber, analisar e avaliar os impactos das ações públicas e privadas, assim como o impacto de suas próprias ações sobre o solo e, portanto, sobre o meio ambiente (VAN BAREN et al., 1998 apud MUGGLER et al., 2006). Para tal, as inter-relações entre as pessoas em si e delas com o ambiente precisam ser construídas considerando o pensar com os outros, sejam esses outros nós, natureza ou todas as vidas, pois mesmo que haja o nível pessoal imaginativo e que traduza os pensamentos em linguagens, podemos construir outros modos que envolvam tanto o "eu" como o "outro" na direção do cuidado e afetividade.

Por fim, fica-se claro que a mitigação dos conflitos socioambientais numa bacia hidrográfica, só pode ser obtida por meio de programas de Educação Ambiental, devendo este estar vinculado à identificação dos conflitos socioambientais, representados aqui por todas as atividades exercidas pelos diversos atores sociais, pertencentes à bacia hidrográfica, como forma de conhecer as relações de causa e efeito sobre a gestão dos recursos hídricos segundo a pedagogia dialógica-problematizadora Freireana, seguido pela implementação de um programa de Educação Ambiental que atuem como um instrumento de fortalecimento das comunidades usuárias destes recursos. 


\section{CONSIDERAÇÕES FINAIS}

Diante da complexidade das questões que afetam a região hidrográfica da bacia do rio Grande e na busca de um entendimento e na mitigação destas, torna-se necessário a integração da sociedade civil com os poderes públicos, fundamental para gestão participativa e o planejamento adequados de uso dos recursos hídricos desta bacia e alcançados pela implementação de programas de Educação Ambiental, a fim de provocar mudanças de valores e posturas coletivas, de forma que as experiências e observações do meio ambiente contribuam para a percepção do sujeito quanto a sua relação com o meio ambiente e sua responsabilidade para com ele. Para tal, é indispensável à cooperação local, nacional e global para prevenir e resolver os problemas ambientais com enfoque de cooperação entre agricultores, comunidades e Estado.

A abordagem de temas como agrotóxicos, poluição das águas, assoreamento pelos agricultores requer a apresentação de alternativas agrícolas economicamente viáveis com vistas à promoção de mudanças das técnicas habituais e comuns.

Várias propostas devem ser analisadas a fim que se façam um planejamento de uso racional dos recursos hídricos na bacia do rio Grande tais como: estudo da viabilidade ambiental do atual modelo de irrigação; utilização de um manejo adequado nas áreas limites da bacia hidrográfica; revisão das demandas de água pelos usuários segundo suas demandas efetivas; monitoramento da disponibilidade e qualidade hídrica da região; elaboração do Plano Estadual de Recursos Hídricos, e principalmente, a criação do Comitê da bacia hidrográfica do rio Grande.

\section{REFERÊNCIAS BIBLIOGRÁFICAS}

1. AIVARENGA, R. C.; PORFIRIO-DA-SILVA, V.; GONTIJO NETO, M.M.; VIANC, M.C.M.; VILELA, L. (2010). Sistema Integração Lavoura- Pecuária-Floresta: condicionamento do solo e integração da produção de lavouras. Informe Agropecuário, 31(257), 59-67.

2. BERGMANN, M.; PEDROZO, C. S. (2008). Explorando a bacia hidrográfica na escola: contribuições à educação ambiental. Ciência \& Educação, 14(3), 537-553.

3. BERLINCK, C. N.; CALDAS, A. L. R.; MONTEIRO, A. H. R. R.; SAITO, C. H. S. (2003). Contribuição da educação ambiental na explicitação e resolução de conflitos em torno dos recursos hídricos. Ambiente e Educação, 8, 117-129.

4. BEZERRA, T. M. O.; FELICIANO, A. L. P.; ALVES, A. G. C. (2008). Percepção ambiental de alunos e professores do entorno da estação ecológica de caetés - região metropolitana do Recife PE. Revista Biotemas, 21(1), 147-160.

5. BRASIL: Lei 4.771, de 15 de setembro de 1965 (1965). Institui o novo Código Florestal. Brasília, DF: DOU de 16/09/1965 e retificado em 28/09/1965.

6. BRASIL: Lei 9.795, de 27 de abril de 1999 (1999), que dispõe sobre a educação ambiental, institui a Política nacional de Educação Ambiental. Brasília, DF: DOU de 28/04/1999.

7. BRASIL: Lei 9.985, de 18 de julho de 2000 (2000), que institui o Sistema Nacional de Unidades de Conservação da Natureza. Brasília: DOU 19/07/2000.

8. BRASIL. (2010). Plano de Ação para Prevenção e Controle do Desmatamento e das 
Queimadas no Cerrado- "Conservação e Desenvolvimento". Brasília: MMA. Disponível em: <www.mma.gov.br/estruturas/201/_arquivos/ppcerrado_201.pdf>. Acesso em: jan. 2014.

9. BRYANT, R.L.; BAILEY, S. (1997.) A politicised enviroment. In: Third World Political Ecology. USA: Routledge.

10. CARVALHO, E. K. M. A.; SILVA, M. M. P.; CARVALHO, J. R. M. (2012). Percepção ambiental dos diferentes atores sociais de Vieirópolis, PR. Qualit@s Revista Eletrônica, 13(1), 1-11.

11. CUNHA, I. A. (2006). Fronteiras da gestão: os conflitos ambientais das atividades portuárias. RAP, 40(6), 1019-1040.

12. DIAS, G. F. (2010). Educação Ambiental: princípios e práticas. In: Bernardes, M. B. J.; Prieto, E. C. Educação Ambiental: Disciplina versus tema transversal. Revista Eletrônica do Mestrado em Educação Ambiental, 24, 173-185.

13. FREIRE, P. (1987). Pedagogia do oprimido. Rio de Janeiro: Paz e Terra.

14. GUADAGNIN, J.; SILVA JÚNIOR; J.; SANTOS, P. S. (2011, abril-setembro). Avaliação da vegetação ciliar no município de Barreiras/BA no ano de 2008 utilizando Sensoriamento Remoto e Sistema de Informação Geográfica. In: Anais XV Simpósio Brasileiro de Sensoriamento Remoto - SBSR, Curitiba, PR, Brasil, 30 - 05.

15. JACOBI, P. R.; TRISTÃO, M.; FRANCO, M. I. G. C. (2009). A função social da educação ambiental nas práticas colaborativas: Participação e Engajamento. Caderno Cedes, 29(77), 63-79.

16. LIMA, A. M. M.; PONTE, M. X. (2009). O estudo da paisagem e o planejamento estratégico como bases da gestão da oferta hídrica no Estado do Pará: discussão teórica e metodológica. Geociências, 28(3), 319-332.

17. MARQUES, M. N.; COTRIM, M. B.; PIRES, M. A. F. (2007). Avaliação do impacto da agricultura em áreas de proteção ambiental, pertencentes à bacia hidrográfica do rio Ribeira de Iguape, SP. Química Nova, 30(5), 1171-1178.

18. MELAZO, G. C. (2005). Percepção ambiental e educação ambiental: uma reflexão sobre as relações interpessoais e ambientais no espaço urbano. Olhares \& Trilhas, 6, 45-51.

19. MERTEN, G. H.; MINELLA, J. P. (2002). Qualidade da água em bacias hidrográficas rurais: um desafio atual para a sobrevivência futura. Agroecologia e Desenvolvimento Rural Sustentável, 3(4), 33-38.

20. MOREIRA, M. C.; SILVA, D. D. (2010). Atlas hidrológico da bacia hidrográfica do rio Grande. Barreiras, BA: Editora Gazeta Santa Cruz.

21. OLIVEIRA, C. S. (2009). A "insustentabilidade" do conceito de desenvolvimento sustentável. In: CORRÊA, M. L.; PIMENTA, S. M.; ARNDT, J. R. L. Turismo, sustentabilidade e meio ambiente: contradições e convergências. (p.73-92), Belo Horizonte: Autêntica Editora.

22. OLIVEIRA JÚNIOR, J. C.; DIAS, H. C. T. (2005). Precipitação efetiva em fragmento secundário da Mata Atlântica. Revista Árvore, 29(1), 9-15.

23. PORTO, M. F. A.; PORTO, R. L.L. (2008). Gestão de bacias hidrográficas. Estudos avançados, 22(63), 43-60.

24. REIGOTA, M.; SANTOS, R. F. (2005). Responsabilidade social da gestão e uso dos recursos naturais: o papel da educação no planejamento ambiental. In: PHILIPPI JR., A.; PELICIONI, 
M.C.F. Educação ambiental e sustentabilidade. (p.849-863), Barueri, SP: Manole.

25. SAITO, C.H. (2009). Educação ambiental no Brasil e a crise socioambiental Mundial. Espaço em Revista, 11(2), 1-14.

26. SAITO, C.H.; BASTOS, F.P., ABEGG, I. (2008). Teorias-guia educacionais da produção dos materiais didáticos para a transversalidade curricular do meio ambiente do MMA. Revista Iberoamericana de Educación, 45, 1-10.

27. SANTOS, I. A.; SAITO, C. H. (2006). A mitificação da participação social na política nacional de recursos hídricos - gênese, motivação e inclusão social. Geosul, 21(42), 7-27.

28. SCOTTO, G. (2011). Conflitos ambientais no Brasil: natureza para todos ou somente para alguns? In: SAITO, C. H.; RUSCHEINSKY, A.; BASTOS, F. P.; NUNES, J. B. A.; SILVA, L. F.; CARVALHO, L. M. Conflitos Socioambientais, Educação Ambiental e Participação Social na Gestão Ambiental. Sustentabilidade em Debate, 2(1), 121-138.

29. SILVA, L. M. C.; LANNA, A. E. L. (1997, novembro). Critérios de outorga de uso da água com base em modelagem agro-hidrológica: metodologia e aplicação (bacia do rio Branco - BA). In: Anais do XII Simpósio Brasileiro de Recursos Hídricos, Vitória, ES, Brasil, 16-20.

30. SPADOTTO, C. A.; GOMES, M. A. F.; LUCHINI, L.C.; ANDRÉA, M.M. (2004). Monitoramento do Risco Ambiental de Agrotóxicos: princípios e recomendações. Jaguariúna, SP: Embrapa Meio Ambiente.

31. SUASSUNA, D. M. F. A. (2005). Entre a dominação racional-legal e o carisma: o projeto Tamar e sua intervenção em comunidades pesqueiras do litoral brasileiro. Sociedade e Estado, 20(3), 521-539.

32. TUNDISI, J. G.; MATSUMURA-TUNDISI, T. (2011). Recursos Hídricos no século XXI. São Paulo: Oficina de Textos.

33. VAN BAREN, H.; MUGGLER, C.C.; BRIDGES, E.M. (2006). Soil reference collections and expositions at district level: Environmental awareness and community development. In: MUGGLER, C. C.; SOBRINHO, F. A. P.; MACHADO, V. A. Educação em solos: princípios, teoria e métodos. Revista Brasileira de Ciências do Solo, 30, 733-740. 